\section{AB0791 THE DIAGNOSIS VALUE OF SYNOVIAL FLUID LYMPHOCYTE IN GOUT PATIENTS}

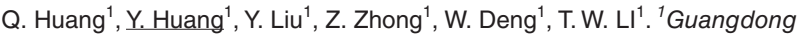
Second Provincial General Hospital, Department of Rheumatology and Immunology, Guangzhou, China

Background: Synovial fluid cell counts have long been recognised to have utility in the diagnosis and management of arthritis. Few studies have explained the diagnosis value of synovial fluid cell counts in gout patients.

Objectives: The study aims to investigate the diagnosis value of synovial fluid cell counts in gout patients.

Methods: A total of 185 gout, 64 rheumatoid arthritis(RA), 26 axial spondyloarthritis(axSpA) and 24 osteoarthritis(OA) patients were included into the study. According to serum uric acid(sUA) level on attack, gout patients were divided into normal sUA gout patients and high sUA gout patients. The laboratory data was recorded and ROC curve was performed.

Results: The synovial fluid WBC, PBMC, monocyte, PMN and neutrophil in gout patients were higher than $O A$ patients $(P<0.05)$. The synovial fluid PBMC and lymphocyte in gout patients were lower than RA and axSpA patients $(P<0.05)$. Compared with RA, axSpA and OA patients, ROC curve showed that the AUC value of lymphocyte and sUA for gout were 0.728 and 0.881 , which were higher than other variables. The optimal cut off value of lymphocyte for gout was 1.362 , with sensitivity of $83.3 \%$ and specificity of $60.6 \%$. The AUC value of lymphocyte and sUA for normal sUA gout patients were 0.694 and 0.643 , which were higher than other variables. The optimal cut off value of lymphocyte for normal sUA gout patients was 1.362 , with sensitivity of $81.6 \%$ and specificity of $60.6 \%$.

Conclusion: Synovial fluid cell counts of gout patients were different from RA, axSpA, and OA patients. Synovial fluid lymphocyte had a higher diagnosis value for gout. REFERENCES:

[1] Scanu A, Oliviero F, Ramonda R, et al. Cytokine levels in human synovial fluid during the different stages of acute gout: role of transforming growth factor $\beta 1$ in the resolution phase. Ann Rheum Dis. 2012, 71(4): 621-4.

Table 1. Basic characteristics of the participants

\begin{tabular}{|c|c|c|c|c|c|}
\hline & Gout(n=185) & $\mathrm{RA}(\mathrm{n}=64)$ & axSpA $(n=26)$ & $O A(n=24)$ & $P$ value \\
\hline Age (years) & $48.58 \pm 15.58$ & $56.19 \pm 12.39^{*}$ & $32.96 \pm 15.19^{* \#}$ & $69.63 \pm 12.43^{* \# \&}$ & $<0.001$ \\
\hline Gender (male/female) & $176 / 9$ & $11 / 53$ & $21 / 5$ & $8 / 16$ & $<0.001$ \\
\hline WBC $\left(\times 10^{9} / L\right)$ & $18.58 \pm 22.94$ & $22.24 \pm 20.87$ & $15.52 \pm 15.03$ & $3.03 \pm 5.59^{* \# \&}$ & 0.002 \\
\hline $\operatorname{PBMC}\left(\times 10^{9} / \mathrm{L}\right)$ & $1.85 \pm 1.99$ & $3.68 \pm 2.43^{*}$ & $3.85 \pm 3.34^{*}$ & $0.74 \pm 1.01^{* \# \&}$ & $<0.001$ \\
\hline Monocyte $\left(\times 10^{9} / \mathrm{L}\right)$ & $1.02 \pm 1.59$ & $1.24 \pm 1.11$ & $1.34 \pm 1.52$ & $0.29 \pm 0.37^{\star \# \&}$ & 0.030 \\
\hline $\operatorname{PMN}\left(\times 10^{9} / \mathrm{L}\right)$ & $16.77 \pm 21.51$ & $18.57 \pm 19.32$ & $15.75 \pm 24.17$ & $2.30 \pm 5.00^{* \# \&}$ & 0.008 \\
\hline Lymphocyte ( $\left.\times 10^{9} / L\right)$ & $0.80 \pm 0.83$ & $2.43 \pm 1.76^{\star}$ & $2.50 \pm 2.04^{*}$ & $0.45 \pm 0.80^{\# \&}$ & $<0.001$ \\
\hline Eosinophil $\left(\times 10^{9} / \mathrm{L}\right)$ & $1.32 \pm 3.75$ & $0.56 \pm 0.93$ & $0.11 \pm 0.17$ & $0.49 \pm 1.85$ & 0.098 \\
\hline Neutrophil $\left(\times 10^{9} / \mathrm{L}\right)$ & $16.42 \pm 21.16$ & $18.82 \pm 20.89$ & $11.13 \pm 14.23$ & $2.23 \pm 4.87^{* \#}$ & 0.003 \\
\hline $\mathrm{UA}(\mu \mathrm{M})$ & $497.92 \pm 132.24$ & $299.31 \pm 97.91$ & $351.81 \pm 118.93^{*}$ & $333.38 \pm 75.19^{*}$ & $<0.001$ \\
\hline $\operatorname{ESR}(\mathrm{mm} / \mathrm{h})$ & $61.02 \pm 37.68$ & $82.42 \pm 32.87^{*}$ & $68.12 \pm 36.25$ & $42.34 \pm 35.91^{* \# \&}$ & $<0.001$ \\
\hline $\mathrm{CRP}(\mathrm{mg} / \mathrm{L})$ & $56.52 \pm 45.64$ & $44.01 \pm 35.27^{*}$ & $65.49 \pm 39.85^{\#}$ & $22.11 \pm 40.65^{* \# \& ~}$ & $<0.00$ \\
\hline
\end{tabular}

" $P<0.05$ vs gout group, ${ }^{\#} P<0.05$ vs RA group, ${ }^{\&} P<0.05$ vs axSpA group

Disclosure of Interests: None declared

DOI: 10.1136/annrheumdis-2021-eular.1992

\section{AB0792 IMAGING METHODS IN PREDICTING A RADIOLOGIC PROGRESSION IN RA}

O. Alekseeva ${ }^{1}$, D. Kudinsky2, A. Smirnov2, A. Volkov2, E. Nasonov ${ }^{3} .{ }^{1}$ V.A. Nasonova Research Institute of Rheumatology, Diagnostic Department, Moscow, Russian Federation; ${ }^{1}$ V.A. Nasonova Research Institute of Rheumatology, Diagnostic Department, Moscow, Russian Federation; ${ }^{3}$ V.A. Nasonova Research Institute of Rheumatology, Chief Researcher, Moscow, Russian Federation

Background: Rheumatoid arthritis (RA) is the chronic inflammatory joint disease, and it is responsible for structural damage. Several studies have shown that ACPA + patients were more likely than ACPA- patients to develop erosive changes on radiography. Ultrasound (US) is a well-established method of diagnosis and follow-up in RA, which at the moment may have a prognostic value in assessing the outcomes of the disease.

Objectives: to identify the prognostic role of US in radiologic progression in RA patients.

Methods: 85 RA pts, mean age 53,0 [44,0;61,0] yrs, mean disease duration 8 $[4 ; 24]$ months were treated with MTX and biologics according to Treat-To-Target concept. Among them 56 patients with early RA, mean age 53,5 [45,5; 61,0], disease duration $5[3 ; 7,5]$ months. Hands and feet ultrasound (US) with gray scale (GS), power Doppler (PD) and destructive changes (erosion), according to the criteria of OMERACT, were analyzed before initiation of treatment and in 3, 6, 9 and 12 months after. A binary scoring system (presence/absence of erosions) of the joints examined was used. Radiographs were obtained at baseline and 4 years, radiographic changes were assessed using Sharp/van der Heijde modified scoring method. Radiographic progression was documented based on Sharp/Van der Heijde modified score changes during the follow up.

Results: 71 ACPA+ (84\%) and 14 ACPA- (16\%) patients presented among the 85 patients with RA, among them $49 \mathrm{ACPA}+(87 \%)$ and $7 \mathrm{ACPA}-(13 \%)$ with early RA RA progression by 4 years the follow-up period was identified in $39 \%$ of pts. During the follow-up period 33 of 85 patients had radiographic progression: the count of erosion increased from $0[0 ; 3]$ to $2[0 ; 6]$. At the same time, on the background of therapy, a decrease in ultrasound signs of inflammation was determined according to the GS and PD: from $6[4 ; 9]$ to $1[0 ; 2] p=0.000$ and from 2 $[1 ; 6]$ to $0[0 ; 1] p=0.000$, respectively, and increase in the number of joints with erosions (from $1[0 ; 2]$ to $2[0 ; 4], p=0.000$ )

In the group with early RA, the changes were similar.

In ACPA+ general group the count of erosion at 4 years was significantly higher than in ACPA-general group $(3[0 ; 7]$ and $0[0 ; 1]$, respectively, $p=0.0026)$

In ACPA+ early RA group the number of joints with erosions by US at baseline was significantly higher than in ACPA- early RA group $(1[0 ; 1]$ and $0[0 ; 0]$ respectively, $p=0.017)$. In $A C P A+$ early $R A$ group the count of erosion at 4 years was significantly higher than in ACPA- early RA group $(2[0 ; 4]$ and $0[0 ; 0]$ respectively, $\mathrm{p}=0.009$ ) (Table 1 )

Table 1. Characteristic of the groups (general group)

\begin{tabular}{|c|c|c|c|}
\hline at baseline & $\mathrm{ACPA}+(71 \mathrm{pts})$ & ACPA- (14 pts) & p \\
\hline The number of joints with erosions by US & $1[0 ; 2]$ & $0[0 ; 1]$ & 0,36 \\
\hline $\begin{array}{l}\text { The number of erosions by X-ray } \\
\text { after } 4 \text { years follow up }\end{array}$ & $1[0 ; 4]$ & $0[0 ; 1]$ & 0,06 \\
\hline The number of joints with erosions by US & $2[0 ; 4]$ & $1[0 ; 2]$ & 0,16 \\
\hline The number of erosions by X-ray & $3[0 ; 7]$ & $0[0 ; 1]$ & 0,0026 \\
\hline $\begin{array}{l}\text { Characteristic of the groups (early RA group) } \\
\text { at baseline }\end{array}$ & ACPA+(49 pts) & ACPA- (7 pts) & p \\
\hline The number of joints with erosions by US & $1[0 ; 1]$ & $0[0 ; 0]$ & 0,017 \\
\hline $\begin{array}{l}\text { The number of erosions by } \mathrm{X} \text {-ray } \\
\text { after } 4 \text { years follow up }\end{array}$ & $0[0 ; 2]$ & $0[0 ; 0]$ & 0,11 \\
\hline The number of joints with erosions by US & $2[0 ; 3]$ & $1[0 ; 1]$ & 0,22 \\
\hline The number of erosions by $\mathrm{X}$-ray & $2[0 ; 4]$ & $0[0 ; 0]$ & 0,009 \\
\hline
\end{tabular}

Conclusion: Thus, in early RA is advisable to perform an US of the hands and feet to select a group of patients with potentially rapid radiological progression. US evaluation of patients with non-early stage RA is not very important for assessing the prognosis.

Disclosure of Interests: None declared

DOI: 10.1136/annrheumdis-2021-eular.2431

\section{AB0793 $\quad$ CONTRIBUTION OF INVESTIGATIONS FOR THE QUEST OF PRIMITIVE CANCER IN FRONT OF BONE} METASTASIS

S. Boussaid ${ }^{1}$, S. Rekik ${ }^{1}$, S. Mechergui ${ }^{1}$, S. Jemmali ${ }^{1}$, E. Cheour ${ }^{1}$, H. Sahli ${ }^{1}$ M. Elleuch ${ }^{1}{ }^{1}$ Rabta Hospital, Rheumatology Department, Tunis, Tunisia

Background: Bone metastases (OM) or secondary cancers bones are bony locations of tumor cells, away from a primary malignant tumor. The Bone metastases are the most common metastases. They can be revealing in 20 to $30 \%$ cases or complicate the course of a known cancer. The bone metastases are a pejorative prognostic factor. Objectives: The aim of this study was to identify the Contribution of diagnostic methods for the quest of primitive cancer in presence of bone metastasis.

Methods: We conduct a retrospective study of 35 files of patients who were hospitalized in the rheumatology department. All patients underwent a questionnaire and a clinical examination. Additional radiological assessment, bone biopsies, biopsies of othe sites, bone scintigraphy and tumor markers were carried out on a case-by-case basis. Results: Thirty-five cases (25 men and 10 women) were analysed. The average age was 61 years [45-85]. Seven patients had a known history of neoplasia. One or more bone biopsies were performed in 8 cases. The vertebrae were the most biopsied bone site ( 6 cases). The bone biopsies were in favour of carcinoma ( 3 cases), adenocarcinoma ( 2 cases), squamous cell carcinoma ( 1 case) and inconclusive (2 cases) Non bony biopsies ( 2 pulmonary, 2 prostatic, 1 mammary) concluded to an adenocarcinoma ( 3 cases) and a carcinoma ( 2 cases). Bone scintigraphy was carried out in 7 cases and showed in all cases diffuse or localized hyperfixation. The localized value of tumor markers appeared relatively low except for Prostate Specific Antigen (PSA). Other metastatic localisations were identified: hepatic (6 cases) and pulmonary ( 1 case). The primary cancer identified was pulmonary for 11 patients, prostatic for 7 , gynaecological for 4 and digestive for 3 . One patient had Otorhinolaryngological cancer and another had bone cancer. Bone biopsy allowed the diagnosis in 6 cases (17\%). The primary cancer was discovered by a biopsy of other non-bone sites in 5 cases (14\%). Neoplastic antecedents and clinical context were considered sufficient in 16 cases $(45 \%)$. Primary cancer remained undetermined in 8 cases $(22 \%)$.

Conclusion: Bone biopsy, as well as non-bone biopsy, remains an essential tool in the etiological diagnosis of bone metastases. They are very contributive in the same proportions. PSA is a major diagnostic asset in the search for primary cancer 